\title{
Fase de desinvestimento da carreira docente de professores de Educação Física
}

\author{
Margareth Porath* \\ Priscila Jochem ** \\ Alexandra Folle*** \\ Gelcemar Oliveira Farias ${ }^{* * * *}$ \\ Juarez Vieira do Nascimento ${ }^{* * * * *}$
}

Resumo: O objetivo deste estudo foi analisar a fase de desinvestimento profissional de professores de Educação Física. Neste estudo de casos de histórias de vida participaram quatro professores de Educação Física, com mais de vinte e cinco anos de intervenção profissional no magistério público estadual de Florianópolis. Na coleta de dados foram utilizadas entrevistas semiestruturadas, as quais foram analisadas por meio da técnica de análise de conteúdo. As evidências encontradas retratam o desinvestimento amargo pautado pelo descaso governamental, sendo que o desinvestimento sereno é retratado pelo período de afastamento da docência, o qual os docentes poderão investir em seus projetos pessoais.

Palavras-chave: Desinvestimento sereno. Desinvestimento amargo. Carreira docente. Educação Física.

\footnotetext{
"Mestranda em Educação Física pela Universidade Federal de Santa Catarina. E-mail: esportivo.porath82@yahoo.com.br

"Professora de musculação e natação na Academia Aqualine em São José/SC e Árbitra da categoria Nacional da Confederação Brasileira de Voleibol (CBV) e Federação Internacional de Voleibol (FIVB). E-mail: porath82@yahoo.com.br

"'Docente do Curso de Educação Física do Centro de Ciências da Saúde e do Esporte da Universidade do Estado de Santa Catarina. E-mail: afolle_12@hotmail.com

"*.'Pós-Doutorando na Universidade Federal de Santa Catarina. E-mail: fariasgel@hotmail.com

...*A Atualmente é Professor Associado III da Universidade Federal de Santa Catarina (UFSC) e Diretor do Centro de Desportos da UFSC. E-mail: juarezvn@cds.ufsc.br
} 


\section{INTRODUÇão}

As investigações sobre a carreira docente têm revelado que ela pode ser entendida através das diferentes fases ou etapas pelas quais passa um professor ao longo da sua atuação profissional, desde sua inserção até a aposentadoria ou afastamento do contexto laboral (FEIMAN-NEMSER, 1982; BURKE et al., 1987; RODRIGUES, 1987; BARONE et al., 1996; STROOT, 1996; NASCIMENTO; GRAÇA, 1998; HUBERMAN, 2000; GONÇALVES, 2000; STEFY et al., 2000; FARIAS, 2010). Estes períodos, que iniciam com o ingresso no mercado de trabalho e se estendem até a ruptura com a carreira docente, são assinalados por sucessivos momentos, os quais se articulam na construção de conhecimentos e experiências originadas da atuação profissional (FARIAS, 2010).

O último ciclo da carreira docente é compreendido de diferentes formas, dependendo da abordagem adotada pelos autores consultados. Nascimento e Graça (1998) veem esta etapa como um momento de estabilização, no qual os professores apresentam-se questionadores de si próprios e do ensino. Farias (2010) a denomina maturidade, caracterizada pelo conhecimento tácito, nela se apresentando a aposentadoria como um sentimento de realização pessoal e profissional.

Gonçalves (2000) classifica esta fase tanto como um momento de renovação do interesse pela escola e pelos alunos, quanto como um período de desencanto, no qual os professores demonstram cansaço, saturação, impaciência, estando ansiosos pela aposentadoria e tornando-se incapazes de ouvir e suportar as crianças. De modo similar, Huberman (2000) descreve que o desinvestimento da carreira docente é marcado pela libertação progressiva do investimento no trabalho, o substituindo pela dedicação a interesses exteriores à escola e a uma vida social de maior reflexão. Este momento pode ser vivido de forma positiva, correspondendo a um 'desinvestimento sereno' ou de forma negativa, marcando um 'desinvestimento amargo'.

Ao ampliar a fase final do percurso profissional para o momento em que os professores se aposentam, porém continuam a contribuir 
com a educação, Steffy (2000) denomina estes profissionais de professores eméritos. Em tal situação, alguns se movem para posições administrativas, outros se dedicam a novos princípios educativos.

No intuito de investigar a fase final da carreira docente em Educação Física, ressalta-se que os professores, de acordo com sua trajetória, realizam a avaliação retrospectiva da sua profissão, contemplada por ações mediadas no ambiente de trabalho, relações interpessoais, profissionalidade, sentidos e significados atribuídos a suas experiências, entre outros fatores.

Nesta perspectiva, utilizou-se a classificação de Huberman (2000), nomeada 'fase de desinvestimento' para identificar os professores desta etapa de desenvolvimento profissional. Isto não significa, todavia, que os professores, neste instante, desinvistam totalmente de suas ações educativas, o que ocorre é a aproximação da aposentadoria e, ao mesmo tempo, de uma nova etapa da vida pessoal, desencadeando o recuo de seus interesses profissionais em favor dos interesses pessoais. A partir deste entendimento, o objetivo do estudo foi analisar a fase de desinvestimento profissional de professores de Educação Física do magistério público estadual de Santa Catarina.

\section{Procedimentos metodológicos}

A investigação caracteriza-se como estudo de casos de histórias de vida, com abordagem qualitativa das informações. A maioria dos estudos qualitativos é conduzida com amostras pequenas e, em alguns casos, o investigador limita-se a estabelecer uma caracterização minuciosa de um único sujeito, tendo como objetivo "[...] captar a interpretação que determinada pessoa faz da sua própria vida" (BOGDAN; BIKLEN, 1994, p. 17).

Os participantes do estudo foram professores de Educação Física com mais de vinte e cinco anos de intervenção profissional, no magistério público estadual da cidade de Florianópolis (SC). Optouse por este período de atuação, pois a literatura indica que professores 
com mais de 20 anos de atuação já se aproximam da fase final da carreira docente (GONÇALVES, 2000; STEFFY et al., 2000; FARIAS, 2010). Investigaram-se quatro professores de Educação Física, pelos seguintes critérios: ser professor efetivo de Educação Física no magistério público estadual; ter mais de vinte e cinco anos de intervenção profissional no magistério público estadual; atuar em sala de aula. Os critérios de exclusão foram: estar aposentado; estar afastado da docência, exercendo cargos administrativos na escola ou na secretaria estadual de educação; estar afastado da escola por qualquer tipo de licença. Assim, foram selecionados como sujeitos da pesquisa:

*professor A: 50 anos de idade e 28 anos de atuação no magistério público estadual de Santa Catarina. Efetivou-se no ano de 1981. Atua nos três níveis da educação básica (educação infantil, ensino fundamental e médio). Assumiu cargo comissionado de diretor de escola de 1986 a 1987. Além das 40h no magistério estadual, atua $10 \mathrm{~h}$ em escola particular, há 26 anos;

*professor B: 56 anos de idade e 32 anos de atuação no magistério público estadual de Santa Catarina. Efetivou-se no ano de 1978. Atua em diversos níveis da educação infantil e do ensino fundamental. Assumiu cargo de diretor de escola, nos períodos de 1991 a 1995 e de 1999 a 2003. Além das 40h no magistério estadual, é árbitro estadual e nacional, desde 1976, e foi árbitro internacional de 1990 a 2007. Atualmente, também exerce cargo de coordenador e instrutor de arbitragem;

*professora C: 49 anos de idade e 29 anos de atuação no magistério público estadual de Santa Catarina. Efetivou-se no ano de 1981. Atua em diversos níveis da educação infantil e do ensino fundamental. Assumiu cargo de secretária de escola, nos períodos de 1991 a 1993, 1996 a 1998, 2001 a 2006, e o de diretora de escola, nos anos de 1995 a 1996 e 1998. Foi assistente na Secretaria de Educação, nos anos de 2000 e 2001;

*professora D: 49 anos de idade e 27 anos de atuação no magistério público estadual de Santa Catarina. Efetivou-se no ano 
de 1981. Atua nos três níveis da educação básica (educação infantil, ensino fundamental e médio). Assumiu cargo de diretora eleita de escola de 1991 a 1993.

$\mathrm{Na}$ coleta de dados foram utilizadas entrevistas semiestruturadas direcionadas aos professores investigados e a alguns de seus colegas de trabalho (um representante da esfera administrativa, um representante da esfera pedagógica e um colega do corpo docente). Na seleção dos colegas de trabalho, foi solicitado aos próprios professores, sujeitos da pesquisa, que indicassem quais os representantes de cada uma das esferas que poderiam contribuir com informações sobre sua fase final de carreira, no magistério público estadual de Santa Catarina. Destaca-se que a opção por representantes das três esferas ocorreu pelo interesse em obter informações de sujeitos que exercessem diferentes funções dentro da escola (diretor, secretário, orientador educacional, professor de Educação Física ou outras disciplinas) e, assim, mantivessem diferentes relações profissionais e pessoais com os professores de Educação Física. Os colegas selecionados pelos professores ficaram assim definidos:

*professor A: diretora, orientadora educacional, professor de Educação Física;

*professor B: administradora, orientadora educacional, professora de Educação Física;

*professora C: diretora, orientadora educacional, professora de Geografia;

*professora D: secretária, orientadora educacional, professora de Educação Física.

A triangulação das informações, obtidas nas entrevistas com os colegas de trabalho, buscou aprofundar o conhecimento sobre a fase de desinvestimento profissional docente analisada.

Na trajetória da investigação, primeiro foi encaminhado um ofício à Direção de Recursos Humanos da Gerência de Educação da Secretaria de Estado do Desenvolvimento Regional da Grande 
Florianópolis para que fosse realizado um levantamento dos professores de Educação Física, do magistério público estadual, na cidade de Florianópolis, que possuíam mais de vinte e cinco anos de intervenção profissional. Obtido este levantamento, o projeto de pesquisa foi aprovado tanto pelo Departamento de Ensino Superior da Gerência de Educação da Secretaria de Estado do Desenvolvimento Regional da Grande Florianópolis quanto pelo Comitê de Ética em Pesquisa com Seres Humanos da Universidade Federal de Santa Catarina, sob o parecer 029/08.

Após a aprovação, foi feito o primeiro contato, por telefone, com as secretarias das escolas em que os professores atuavam, a fim de obter as informações necessárias para inclusão ou exclusão dos docentes no estudo. A seleção final dos participantes, conforme os critérios estabelecidos, foi realizada em contato pessoal, no qual foram explicados os objetivos e os procedimentos do estudo e solicitada a assinatura do Termo de Consentimento Livre Esclarecido.

Depois da indicação dos colegas de trabalho para obtenção de dados complementares, realizou-se contato também com eles para explicar-lhes os objetivos do estudo e solicitar sua colaboração para o desenvolvimento da pesquisa.

Inicialmente, foram entrevistados os professores de Educação Física e, em seguida, os colegas de trabalho indicados pelos investigados, de acordo com a disponibilidade de cada um. Todas as entrevistas foram realizadas individualmente; gravadas; transcritas na íntegra para facilitar o processo de análise dos dados; retornadas aos entrevistados (para alterarem e/ou confirmarem as informações contidas na transcrição), como processo de validação de seu conteúdo.

As informações obtidas nas entrevistas semiestruturadas foram analisadas por meio da técnica de análise de conteúdo, a qual foi organizada nas seguintes fases: pré-análise (organização dos documentos); exploração do material (administração sistemática das decisões tomadas); tratamento dos resultados obtidos e sua interpretação (os resultados são tratados de maneira a serem 
significativos e válidos) (BARDIN, 1977). Avalidação das categorias de análise, encontradas no presente estudo, foi realizada por dois professores de Educação Física, com publicações sobre a temática em capítulos de livros e em artigos de periódicos.

\section{ApRESENTAÇÃo E discusSÃo dos RESULTADOS}

Os resultados encontrados neste estudo possibilitaram a identificação de dois sentimentos presentes na fase de desinvestimento da trajetória profissional dos professores de Educação Física da rede estadual de ensino: o desinvestimento sereno (relação ao fato de se afastarem da docência) e o desinvestimento amargo (referente à profissão docente). Embora, nesta fase, ocorra a preocupação mais acentuada com os interesses pessoais em detrimento aos interesses profissionais (HUBERMAN, 2000), o desinvestimento sereno referese à transição tranquila dos docentes para a aposentadoria, sobressaindo-se em sua carreira as experiências positivas e as recordações de sucesso profissional. O desinvestimento amargo é marcado pelos ressentimentos acumulados ao longo da carreira, o que possivelmente pode provocar o sentimento de saudosismo de experiências do passado.

No que se refere à opinião dos professores quanto à Educação, no âmbito geral, verificou-se que os docentes em final de carreira demonstram-se decepcionados com o descaso e o abandono da educação pelo governo estadual. Resultado semelhante foi evidenciado no estudo de Veiga et al. (2007), o qual destacou o sentimento de indiferença relatado por uma professora quanto ao descaso do poder público com a Educação. De modo similar, Alves (1997) relatou que os professores por ele investigados concordaram com a absoluta falta de apoio dos governantes, tornando-se fonte de desilusões para a carreira docente.

No estudo de Farias (2010), observou-se que apesar de os professores sentirem a falta de apoio por parte do governo, eles ainda almejam que o ensino público possa ser a prioridade da educação nacional. Fatores como remuneração salarial e condições 
de trabalho passam a ser os indicativos mais problemáticos aos professores nesta fase, o que gera desconforto e desejo de aposentadoria (BOTH; NASCIMENTO; BORGATTO, 2008).

As mudanças constantes nas leis que fazem referência à aposentadoria docente também foram fortemente evidenciadas nos comentários dos professores de Educação Física, em fase de desinvestimento profissional. A aposentadoria do magistério apresenta-se assim como libertadora de experiências profissionais, constando do plano individual dos educadores (CHINELLI; JUNQUEIRA, 1998). Tal situação é revelada nas falas dos entrevistados:

[...] quando será que eu vou consegui me aposentar? Porque era para a semana que vem, mas não será mais porque eu saí de sala. Então a gente fica meio ansiosa. Eu tenho um pouco de ansiedade, porque a gente não tem muita certeza das coisas do magistério, tem muita coisa mudando e é uma em cima da outra, não sou só eu, são todos os colegas [...] (Professora C).

[...] vou procurar agora na justiça, um amigo meu que é advogado. Porque dizem que há uma brecha na lei, que se você tiver 30 anos você pode se aposentar (Professor B).

A colega do corpo docente do professor B corrobora as afirmações dos professores investigados, dizendo que, por causa das frequentes mudanças que ocorrem na legislação docente, $o$ professor acaba protelando sua aposentadoria. Gonçalves (2000) destaca a impaciência na espera pela aposentadoria como uma das principais características de professores em final de carreira.

A professora $\mathrm{C}$ demonstrou grande insatisfação com a progressão nos planos de cargos e salários da rede estadual de ensino, a qual, segundo ela, "[...] está com a tabela toda achatada. Parou-se no tempo, mudou a idade, mudou o tempo de serviço, mas não se investiu na tabela dos vencimentos dos professores, nada, continua 
igualzinha como era quando era assim: só vinte e cinco anos de serviço". Sua colega do corpo docente corrobora esta postura, ao explicar que a professora $\mathrm{C}$ demonstra frustração com o pouco incentivo para o docente continuar atuando na profissão, pois mesmo que faça um curso de especialização, o aumento salarial não é significativo. A política administrativa de melhoria dos planos de cargos e salários pode contribuir para minimizar o que Santini e Molina Neto (2005) retratam como sentimentos de insegurança, insatisfação e preocupação. A sobrecarga de trabalho, justificada pela excessiva demanda de atividades e a multiplicidade de papéis exercidos na escola, deve também ser revista pelos órgãos dirigentes, no intuito de propor alternativas que reduzam os fatores geradores do esgotamento e do estresse do professor.

No estudo de Alves (1997), os professores investigados manifestaram que se sentem desestimulados em seu trabalho por não haver oportunidades frequentes de promoção na carreira. Nesta perspectiva, de acordo com Valle (2003), os professores, no final de sua carreira profissional, estão marcados, muitas vezes, pelo desencantamento diante de um percurso que prometeu muito e permitiu pouco, tanto em relação às pretensões pessoais quanto às profissionais. Santos, Bracht e Almeida (2009) destacam a interação entre a vida profissional e a vida pessoal do docente. $\mathrm{O}$ equilíbrio das ações do professor, em seu desenvolvimento profissional, reportao a diferentes experiências que marcam sua trajetória, resultando, ao final da carreira, em sentimento de contentamento e em satisfatórias lembranças de ações gerenciadas na sua prática pedagógica e na realização pessoal frente a seu ambiente laboral.

O depoimento mais expressivo de desinvestimento amargo, como sentimento predominante em relação à profissão, foi realizado pelo professor A. Ele revelou não mais sentir prazer em exercer sua profissão, principalmente devido ao descaso do poder público com a Educação e o fato de não poder se aposentar. 
Porque hoje eu não quero mais ficar, hoje eu não tenho mais prazer. Não tenho mais prazer [...] então não quero mais fazer, eu não tenho mais disposição para fazer. Eu ainda sou um cara expansivo, alegre, brincalhão. [...] Por isso eu sofro e hoje não estou mais conseguindo ter essa alegria. Então eu estou 'morrendo aos poucos' dentro da escola (Professor A).

O colega de profissão do professor A corrobora, ao dizer: "Ele está muito descontente com a Educação atual e com o sistema educacional". Explicita que o professor A demonstra estar bastante cansado e desencantado com o ensino público, devido ao tempo de intervenção em sala de aula e das condições de trabalho oferecidas. Os relatos apresentados reforçam a afirmação de Huberman (2000) de que a não correspondência de sucesso, a sensação de desespero, a estagnação no plano profissional conduzem realmente a um desinvestimento amargo.

Em relação à opinião dos professores quanto à Educação Física, no âmbito específico, constatou-se grande preocupação com o futuro desta disciplina escolar e com os futuros profissionais da área que estão se formando. Os professores A e B acreditam que as universidades não estão preparando profissionais capacitados para atuarem nas escolas e resolverem as situações adversas que acontecem neste espaço de intervenção profissional. $\mathrm{O}$ relato, a seguir, exemplifica isto.

Então, está muito difícil. A minha expectativa daqui para frente é de que vai ser muito difícil para quem entrar, vai ser muito difícil. Eu tenho muita pena dessa gurizada nova que está se formando para ser professor de Educação Física, eu tenho muita pena (Professor A).

O professor A relatou que está descontente com o Conselho Regional de Educação Física, o qual, por ser um órgão de âmbito federal e também receber pagamento de anuidade dos professores atuantes no magistério público, deveria fazer mais em prol destes profissionais, "porque para o ensino público, para nós professores de 
Educação Física atuantes na escola, o sindicato (CREF) não fez nada, nada. É um absurdo. [...]. Para a prioridade, o maior dos empregos que é a escola, esse sindicato não tem validade para mais nada" (Professor A).

Enquanto o sentimento de desinvestimento amargo predomina em relação à profissão, o desinvestimento sereno predomina em relação ao fato de brevemente poderem se afastar da docência, passando a ter mais tempo disponível para investimentos pessoais. Professores de Educação Física com diferentes trajetórias, investigados por Santos, Bracht e Almeida (2009), manifestaram que as experiências pessoais e profissionais se entrelaçam ao longo da carreira, predominando as relações interpessoais, o reconhecimento pessoal, as aprendizagens adquiridas no decorrer da intervenção, o que afasta a ideia de ser esta fase marcada pelo pessimismo no campo profissional.

O professor B e a professora $\mathrm{D}$ argumentaram estarem aliviados com a proximidade da aposentadoria, pois estarão disponíveis para elaborar seus projetos pessoais, voltados para outras atividades que não sejam a atuação docente e que se revelem mais gratificantes. A investigação de Borges (1998) encontrou, na Educação Física, um professor que, embora não estando na fase final da carreira docente, apresentou características profissionais similares às encontradas em professores desta fase. Isto pode estar articulado à preocupação com o tempo de trabalho necessário para a aposentadoria e a dedicação às realizações pessoais.

As falas dos colegas de trabalho dos professores investigados reforçam a percepção de seu interesse em se dedicarem a outras atividades após a aposentadoria.

Com certeza ele não deverá voltar à docência porque como ele tem a arbitragem, ele dará continuidade a isso, não voltará para a sala de aula (Colega de profissão A). 
A maioria dos relatos dos colegas mostra sua percepção de que, devido às constantes mudanças na legislação referente ao tempo de serviço e à idade necessários para a aposentadoria, os docentes estão aguardando, com ansiedade, tal momento.

O estudo de Veiga (2007) encontrou informações semelhantes junto a uma professora que, após a aposentadoria, passou a investir em atividades voltadas para seu crescimento cultural, para si mesma, para sua vida social. Huberman (2000) corrobora que, até determinado ponto, os professores, na fase de desinvestimento da carreira docente, apresentam postura positiva, libertando-se progressivamente, sem se lamentarem do investimento no trabalho, e consagrando mais tempo a si próprios, aos interesses externos à escola, a uma vida social de maior reflexão. No entanto, Gonçalves (2000) constatou que a maioria das professoras portuguesas investigadas citou o final da carreira (a partir dos 30 anos de serviço) como um dos momentos críticos no magistério, devido à saturação, ao cansaço, à idade.

Os professores B e D manifestaram que estão se preparando emocional e intelectualmente para abandonar a carreira docente e investir em outras áreas. A professora $\mathrm{C}$, devido à rotina exercida em seu cotidiano de trabalho, espera a aposentadoria sem ansiedade e sem preocupação.

$\mathrm{Eu}$ acho que tem que se preparar emocionalmente, intelectualmente, pois é a mesma coisa que você cortar uma etapa da tua vida. Você tem que se preparar bem e começar a enxergar aquilo que você fez todos esses anos, que você possa utilizar em outras áreas, em outras coisas que você possa não sentir tanto [...] porque cortar não é fácil não (Professor B).

Agora eu vou poder me dedicar às áreas que eu gostaria de ter feito. Para mim será um alívio. Se eu não tivesse nenhum desejo, nenhum objetivo iria ser frustrante, iria ser deprimente parar com tudo. $\mathrm{Eu}$ não iria poder parar, mas como tenho outros objetivos para mim será positiva essa saída, pois 
têm pessoas que quando se aposentam ficam sem objetivo e acabam na depressão, acabam ficando doentes (Professora D).

Eu não estou sentindo este baque, por enquanto. Eu sou assim enquanto eu estou naquela minha rotina do dia-a-dia [...]. Não estou nem pensando, quando chegar a hora vamos ver. Não fico muito assim não, ansiosa, pensando, preocupada (Professora C).

A maioria dos docentes, segundo Chinelli e Junqueira (1998), busca, por meio de outras atividades, a expressão do que é representado como potencialidades subjetivas não realizadas e que podem se associar ou não a uma ruptura eventual ou definitiva com o magistério. As novas ocupações surgem como possibilidade de viabilizar a libertação e o controle do tempo em uma dimensão expressiva da continuidade da vida produtiva.

O professor B manifestou que sairá da docência com a certeza de que valeu a pena e de que nunca será esquecido. Para o professor A, os sentimentos predominantes, neste momento final da docência, reportam-se às lembranças positivas do início de sua carreira e ao afastamento progressivo causado por angústias e descontentamentos nos últimos anos. No desenvolvimento da carreira, os docentes passam por sucessivas experiências que geram ora o sentimento de contemplação, ora o sentimento de frustação, em relação a fatos marcantes. Os professores na fase de desinvestimento, por ser ela o último ciclo da vida profissional, podem revelar fatos e acontecimentos transcorridos nos ciclos anteriores (FOLLE et al., 2009). Este dado pode ser observado na fala do professor A:

Hoje eu tenho dois sentimentos, eu tenho duas formas de ver este meu afastamento. Do início da carreira, eu me lembro daqueles que eu vou ver, vou encontrar, vou abraçar e vou dizer: 'que tempo bom'. E questão de oito, dez anos para cá, quando eu sair eu vou ter que dizer: 'Graças a Deus, Graças a deus'. Porque hoje eu já estou, não sei qual é o grau, mas eu já estou um pouco doente. Hoje eu tenho certeza 
que já estou um pouco doente [...] eu estou muito angustiado. Eu já não tenho mais a alegria de trabalhar que eu tinha antes, por todos aqueles motivos que eu já passei, por todos os motivos (Professor A).

De modo similar à narrativa do professor $\mathrm{A}$, uma docente com mais de vinte e cinco anos de experiência, investigada por Bello (2003), também se mostrou saudosista em relação a determinados períodos de sua vida profissional e aos alunos que encontrou no início da sua carreira, no entanto a vontade de não mais trabalhar nessa função ficou clara em seu depoimento.

As evidências encontradas na investigação revelam que alguns professores de Educação Física, os quais se encontram no final da carreira docente no magistério público estadual de Santa Catarina, apresentam um desinvestimento amargo com relação aos sentimentos individuais pelo fato de brevemente se afastarem da docência. Loureiro (1997) constatou que, para três professores da educação básica, o percurso profissional foi caracterizado pelo desencanto marcado por sentimentos fortemente negativos em relação à profissão, além de a fase de desinvestimento amargo ter predominado no percurso de uma professora com trinta e cinco anos de docência.

$\mathrm{O}$ professor $\mathrm{B}$ admite que poderia ter contribuído de maneira mais expressiva com a educação, mas argumenta que isto não foi possível devido à precariedade de materiais oferecidos pelas escolas. Da mesma forma, a professora de Educação Física investigada por Betti e Mizukami (1997) manifestou que, ao final da carreira, permaneceu o sentimento de que ela poderia ter feito mais pela Educação, devido a seu grande apego à profissão. Após ter percorrido uma trajetória de satisfação profissional, o professor em final de carreira, investigado por Folle et al. (2009), revelou descontentamento com o poder público tanto no que tange à valorização do profissional como devido à falta de condições estruturais para o desenvolvimento do trabalho docente. Esta postura, de maneira branda, acentua-se ao final da carreira, impulsionada talvez pela atitude crítica que os professores desta etapa consolidam.

Confirmando o relato do professor B, o colega do corpo docente 
do professor A afirmou que as condições de trabalho, para os professores de Educação Física, ficam cada vez mais inadequadas, uma vez que, segundo ele, "[...] estamos quase na idade da pedra, com quadro e giz, com uma quadra de cimento e com um material de $5^{\text {a }}$ categoria $[\ldots] "$.

De modo similar, a diretora da escola do professor $\mathrm{C}$ evidenciou que, além da precariedade dos materiais disponibilizados, não há manutenção nem preservação deles. A diretora da escola do professor A disse que esta condição pode resultar em desmotivação para a atuação docente.

[...] pela falta de material, falta de quadra coberta, dia de sol, você não tem onde dar aula. O sol muito quente, dia de chuva também. Isso tudo é pra desanimar qualquer um, realmente desanima. É a mesma coisa que você ir trabalhar e não ter um caderno, não ter um lápis, não ter um giz. Como é que você vai dar aula? (Diretora A).

O desinvestimento amargo sentido pelos professores, com relação aos materiais oferecidos pelas escolas para a intervenção docente, é confirmado no estudo de Alves (1997), o qual mostra a opinião consensual dos professores investigados sobre a necessidade de boas condições de trabalho para que o professor possa melhor render profissionalmente. No estudo com professores de Educação Física, Farias (2010) também constatou o compartilhamento de tais sentimentos, principalmente quando os docentes almejam melhorias nas condições de trabalho, relacionados com os materiais, os equipamentos e o local de atuação.

\section{Considerações finaIS}

As evidências encontradas no estudo com professores de Educação Física, os quais se encontravam na fase de desinvestimento profissional do magistério público estadual de Santa Catarina, permitiram identificar um desinvestimento amargo em relação à Educação de modo geral e à própria Educação Física. Foi possível, 
no entanto, identificar um desinvestimento sereno em relação ao fato de, em breve poderem se afastar da docência.

O sentimento de desinvestimento amargo é compartilhado pelos professores investigados que manifestaram descontentamento com o descaso e o abandono da Educação pelos governantes; com os planos de cargos e salários da rede estadual; com as frequentes mudanças na legislação referente à aposentadoria docente, as quais resultaram em aumento no tempo de atuação profissional, levandoos a adiarem seus novos planos pessoais. Os investigados expressam forte preocupação com o futuro da profissão, assim como com os novos profissionais de Educação Física que estão se formando e se inserindo no contexto escolar.

Com relação ao desinvestimento sereno, os professores argumentam estarem aliviados com a proximidade da aposentadoria, pois assim estarão disponíveis para elaborarem seus projetos pessoais, voltados para outras atividades que não sejam a atuação docente e que se revelem mais gratificantes. Alguns professores esperam o afastamento da carreira docente sem ansiedade nem preocupação. Outros se preparam emocional e intelectualmente para abandonar a docência e investir em outras áreas.

No intuito de ampliar o conhecimento sobre a fase final da carreira docente, sugere-se a continuidade e o aprofundamento dos estudos que enfatizam o desinvestimento profissional dos professores de Educação Física. Eles serão importantes para o desenvolvimento científico da área e para aumentar a compreensão da carreira docente nesta área. 
Teaching Career Disinvestment: a Case Study with State Public Teaching System Physical Education Teachers from Santa Catarina/Brazil Abstract: The present study aimed to analyze the professional disinvestment phase of Physical Education teachers. Four teachers, with more than 25 years of intervention in the Florianópolis' State Public Teaching System, participated in this life histories' case study. In the data collection, semi-structured interviews were used and later analyzed via the content analysis technique. Evidences show a bitter disinvestment caused by governmental neglect, and a serene disinvestment portrayed by the teaching absence, when professionals may invest in their personal life projects.

Keywords: Serene disinvestment. Bitter disinvestment. Teaching career. Physical Education.

Inversión sin retorno en la carrera docente:
estúdio de casos con profesores de Educación
Física de Magisterio Público Estadual de Santa
Catarina
Resumen: El objetivo de este estudio fue analizar la
fase de inversión sin retorno profesional de los
profesores de Educación Física. En este estudio, con
casos de historias de vida, participaron cuatro
profesores de Educación Física, con más de
veinticinco años de intervención profesional en el
magisterio público estadual de Florianópolis. En la toma
de datos fueron utilizados entrevistas semi-
estructuradas, que fueron analizadas por medio de la
técnica de análisis de contenido. Las evidencias
encontradas retratan el triste no retorno económico
pautado por el descaso gubernamental, de forma que
el no retorno sereno de la inversión es reflejado por el
periodo de baja por enfermedad, en el cual los docentes
podrán invertir en sus proyectos personales.
Palabras-clave: Inversión sin retorno serena,
inversión sin retorno amarga. Carrera docente.
Educación Física.




\section{REFERÊNCIAS}

ALVES, F. C. A (in)satisfação dos professores: estudo de opiniões dos professores do ensino secundário do distrito de Bragança. In: ESTRELA, M. T. (Org.) Viver e construir a profissão docente. Porto: Porto Editora, 1997. p. 81-115.

BARDIN, L. Análise de conteúdo. Rio de Janeiro: Edições 70, 1977.

BARONE, T. et al. A future for teacher education: developing a strong sense of profissionalism. In: SIKUKA, J.; BUTTERRY, T. J.; GUYTON, E. (Ed.) Handbook of research on teacher education. New York: Macmillan, 1996. p. 1108-1149.

BELLO, I. M. Contribuições das histórias de vida profissional na formação de professores: limites e possibilidades. Cadernos de Educação, Pelotas, v. 7, n. 1, p. 77-92, 2003.

BETTI, I. C. R.; MIZUKAMI, M. G. N. História de vida: trajetória de uma professora de Educação Física. Motriz, Rio Claro, v. 3, n. 2, p. 108-115, dez. 1997.

BOGDAN, R.; BIKLEN, A. Investigação qualitativa em Educação: uma introdução à teoria e aos métodos. Porto: Porto, 1994.

BORGES, C. M. F. O professor de Educação Física e a construção do saber. Campinas: Papirus, 1998.

BOTH, J.; NASCIMENTO, J. V., BORGATTO, A. F. Percepção da qualidade de vida no trabalho ao longo da carreira docente em Educação Física. Revista Brasileira de Cineantropometria e Desempenho Humano, Florianópolis, v. 10, n. 4, p. 372-378, 2008.

BURKE, P. J. et al. The teacher career cycle. Model development and research report. In: ANNUAL MEETING OF THE AMERICAN EDUCATIONAL RESEARCH ASSOCIATION, 1987, Washington. Anais... Washington: AERA, 1987. p. 1-59.

CHINELLI, F.; JUNQUEIRA, C. Aposentadoria docente, crise de identidade e reinserção no mercado de trabalho. Contemporaneidade e Educação, Salvador, v. 3, n. 4, p. 22-60, dez. 1998.

FARIAS, G. O. Carreira docente em Educação Física: uma abordagem na construção da trajetória profissional do professor. 2010. 303 f. Tese (Doutorado em Educação Física) - Centro de Desportos, Universidade Federal de Santa Catarina, Florianópolis, 2010.

FEIMAN-NEMSER, S. Staff development and learning to teach. In:ANNUAL MEETING OF THE EASTERN EDUCATIONALRESEARCH ASSOCIATION, 1982, Detroit. Anais... Detroit: AERA, 1982. p. 1-18. 
FOLLE, A. et al.. Construção da carreira docente em Educação Física: escolhas, trajetórias e perspectivas. Movimento, Porto Alegre, v. 15, n. 1, p. 25-49, jan./mar. 2009.

FOLLE, A.; NASCIMENTO, J. V. Trajetória docente em educação física: percursos formativos e profissionais. Revista Brasileira de Educação Física e Esportes, São Paulo, v. 24, n. 4, p. 507-523, out./dez. 2010.

FONTOURA, M. M. Fico ou vou-me embora? In: NÓVOA, A. (Org.) Vidas de professores. 2. ed. Porto: Porto, 2000. p. 171-197.

GONÇALVES, J. A. M. A Carreira das Professoras do Ensino Primário. In: NÓVOA, A. (Org.) Vidas de Professores. 2. ed. Porto: Porto, 2000. p. 141-170.

HUBERMAN, M. O ciclo de vida profissional dos professores. In: NÓVOA, A. (Org.) Vidas de professores. 2. ed. Porto: Porto, 2000. p. 31-62.

LOUREIRO, M. I. O desenvolvimento da carreira dos professores. In: ESTRELA, M. T. (Org.) Viver e construir a profissão docente. Porto: Porto, 1997. p. 119-159.

NASCIMENTO, J. V.; GRAÇA, A. A evolução da percepção de competência profissional de professores de Educação Física ao longo da carreira docente. In: CONGRESSO DE EDUCAÇÃO FÍSICAE CIÊNCIAS DO DESPORTO DOS PAÍSES DE LÍNGUA PORTUGUESA, 6., 1998, La Coruña. Actas... La Coruña: INEF Galícia, 1998. p. 320-335.

RODRIGUES, L. Da Prática a teoria: uma experiência em Educação Básica. 1987. 337 f. Tese (Doutorado em Educação) - Unisersidad Faculdad de Ciências de la Educación, Universidad Autônoma de Barcelona, Barcelona, 1987.

SANTINI, J.; MOLINA NETO, V. A síndrome do esgotamento profissional em professores de Educação Física: um estudo da rede municipal de ensino de Porto Alegre. Revista Brasileira de Educação Física e Esportes, São Paulo, v. 19, n. 3, p. 209-222, jul./set. 2005.

SANTOS, N. Z.; BRACHT, V.; ALMEIDA, F. Q. Vida de professores de Educação Física: o pessoal e o profissional no exercício da docência. Movimento, Porto Alegre, v. 15, n. 2, p. 141-165, abr./jun. 2009.

STEFFY, B. E. et al. The model and its application. In: STEFY, B. E.; WOLFE, M. P.; $\mathrm{PASCH}, \mathrm{S}$. H.; ENZ, B. J. (Ed.) Life cycle of the career teacher. California: Kappa Delta Pi, 2000. p. 1-25.

STROOT, S. Organizational socialization: factors impacting beginning teachers. In: SILVERMAN, S. J.; ENNIS, C. (Org.) Student Learning in Physical Education. Champaign: Human Kinetics, 1996. p. 339-365. 
VALLE, I. R. A era da profissionalização: formação e socialização profissional do corpo docente de $1^{\underline{a}}$ a 4⿳亠丷a série. Florianópolis: Cidade Futura, 2003.

VEIGA, I. P. A. et al. Docentes universitários aposentados: ativos ou inativos? Araraquara: Junqueira e Marin, 2007.

\author{
Alexandra Folle \\ Rua José Victor da Rosa, 722 - Bloco A, ap. 105 \\ Barreiros \\ CEP 88117-405 \\ São José/SC
}

Recebido em: 14.09.2011

Aprovado em: 13.12.2011 
